\title{
Frailty and cardiovascular risk in community- dwelling elderly: a population-based study
}

\author{
This article was published in the following Dove Press journal: \\ Clinical Interventions in Aging \\ 6 October 2014 \\ Number of times this article has been viewed
}

\section{Natalia Aquaroni Ricci' \\ Germane Silva Pessoa' \\ Eduardo Ferriolli \\ Rosangela Correa Dias ${ }^{3}$ \\ Monica Rodrigues \\ Perracini'}

'Master's and Doctoral Programs in Physical Therapy, Universidade Cidade de São Paulo (UNICID), São Paulo, ${ }^{2}$ Faculty of Medicine, Universidade de São Paulo (USP), Ribeirão Preto, ${ }^{3}$ Department of Physiotherapy, Universidade Federal de Minas Gerais (UFMG), Belo Horizonte, Brazil
Correspondence: Natalia Aquaroni Ricci Master's and Doctoral Programs in Physical Therapy, Universidade Cidade de São Paulo

Rua Cesareo Galeno, 448 Tatuape,

São Paulo 0307|-000, Brazil

Tel +55 I। 2878 I565

Fax +55 I। 2178 । 3 I0

Email natalia_ricci@hotmail.com
Background: Evidence suggests a possible bidirectional connection between cardiovascular disease (CVD) and the frailty syndrome in older people.

Purpose: To verify the relationship between CVD risk factors and the frailty syndrome in community-dwelling elderly.

Methods: This population-based study used data from the Fragilidade em Idosos Brasileiros (FIBRA) Network Study, a cross-sectional study designed to investigate frailty profiles among Brazilian older adults. Frailty status was defined as the presence of three or more out of five of the following criteria: unintentional weight loss, weakness, self-reported fatigue, slow walking speed, and low physical activity level. The ascertained CVD risk factors were self-reported and/ or directly measured hypertension, diabetes mellitus, obesity, waist circumference measurement, and smoking.

Results: Of the 761 participants, $9.7 \%$ were characterized as frail, $48.0 \%$ as pre-frail, and $42.3 \%$ as non-frail. The most prevalent CVD risk factor was hypertension (84.4\%) and the lowest one was smoking (10.4\%). It was observed that among those participants with four or five risk factors there was a higher proportion of frail and pre-frail compared with non-frail (Fisher's exact test: $P=0.005 ; P=0.021)$. Self-reported diabetes mellitus was more prevalent among frail and pre-frail participants when compared with non-frail participants (Fisher's exact test: $P \leq 0.001$; $P \leq 0.001)$. There was little agreement between self-reported hypertension and hypertension identified by blood pressure measurement.

Conclusion: Hypertension was highly prevalent among the total sample. In addition, frail and pre-frail older people corresponded to a substantial proportion of those with more CVD risk factors, especially diabetes mellitus, highlighting the need for preventive strategies in order to avoid the co-occurrence of CVD and frailty.

Keywords: frailty syndrome, cardiovascular disease, hypertension, aged

\section{Introduction}

Evidence suggests a bidirectional connection between cardiovascular disease (CVD) and the frailty syndrome in the elderly population. ${ }^{1-4}$ Both conditions adversely affect health and decrease the quality of life of older people. ${ }^{1}$ The frailty syndrome is defined as being an increase in the individual's vulnerability to stressors caused by a gradual and progressive abnormal functioning of multiple organ systems, along with a notable dysregulation of the neuroendocrine and immune systems, thereby endangering the homeostasis. ${ }^{5,6}$ The presence of the frailty syndrome varies in community-dwelling elderly from $7 \%$ for those $>65$ years old to $30 \%$ in those who are $\geq 80$ years old. ${ }^{6}$ CVD is present in $60 \%$ of the people $\geq 60$ years and is one of the main causes of death around the world. ${ }^{7}$

The diagnosis of CVD represents a threefold increase in the odds of frailty among the older population. ${ }^{1}$ The relationship between these conditions indicates a common 
pathway in their pathophysiological mechanisms. This could possibly be explained by an abnormal functioning of the inflammatory response, resulting in an increase in inflammatory markers and ultimately leading to chronic inflammation. ${ }^{1-4}$

Similar to other chronic conditions, CVD and frailty have a progressive development over the course of several years and can present a long subclinical phase. ${ }^{8}$ This being so, the prevention and control of risk factors may play an important role in avoiding adverse health outcomes in the aging process. The main modified CVD risk factors are unsuitable eating habits, diabetes mellitus (DM), hypertension, sedentary life style, and smoking. ${ }^{9}$ Middle-aged individuals (ie, 45-69 years old) with more CVD risk factors had higher odds of developing the frailty syndrome. ${ }^{10}$

The early recognition of risk factors for CVD in frail, pre-frail, and non-frail elderly people may change the health/ disease process, prevent disability and loss of independence, decrease health care costs, and reduce mortality rates in the aged population. Thus, the main purpose of this study was to verify the association between CVD risk factors and the frailty syndrome in community-dwelling elderly.

\section{Material and methods}

This is a cross-sectional population-based study derived from the Fragilidade em Idosos Brasileiros (FIBRA) Network for epidemiological research, ie, Network for Studies on Frailty in the Brazilian Elderly. The FIBRA Network is a multicentric project designed to investigate the features and prevalence of the biological frailty syndrome, according to Fried et al's frailty phenotype, ${ }^{6}$ among Brazilian older adults. ${ }^{11}$ The FIBRA Network encompasses 17 Brazilian cities with different human development levels. For this research, data from two Brazilian cities were used. These cities were Barueri and Cuiaba, each of which has less than one million inhabitants and a high human development index (0.785). This research was approved by the Research Ethics Committee of the Pontificia Universidade Catolica de São Paulo (protocol number 269/2007), the Faculdade de Medicina de Ribeirão Preto (protocol number 5018/2007), and the Universidade Cidade de São Paulo (protocol number 13543351).

\section{Participants}

Community-dwelling older adults from urban areas were selected and identified after the enrollment of households within census tracts. The sample size was estimated to have a population proportion of $50 \%$ of a certain characteristic under study ( $\mathrm{p}=50 ; \mathrm{q}=0.50)$, with an error limit of $d=3 \%, d=4 \%$, or $d=5 \%$ and the significance level set at $\alpha=5 \% ; z=1.96$. To calculate sample size, the following formula was used.

$$
\mathrm{n}=\left(\mathrm{z}^{2} \times\left[\mathrm{p} \times \mathrm{q} /\{\mathrm{d}\}^{2}\right]\right)
$$

This resulted in an approximate sample size of 385 subjects for each city with less than one million inhabitants.

The sample was composed of community-dwelling older people, aged $\geq 65$ years, of both sexes. The exclusion criteria were those recommended by Ferrucci et al: ${ }^{12}$ 1) cognitive decline ascertained by the Mini-Mental State Examination, ${ }^{13}$ adjusted according to schooling, ${ }^{14} 2$ ) inability to walk (temporary or permanent) or use of a wheelchair; 3 ) motor impairments and aphasia caused by stroke; 4) Parkinson's disease in the advanced stage or with unstable symptoms; 5) presence of severe sensory deficits that undermine communication; and 6) presence of terminal illness. Older adults with missing or incomplete data related to frailty criteria were also excluded.

Each participant was instructed with regard to the objectives and research procedures, and all provided signed informed consent.

\section{Measures and procedures}

Participants were evaluated by trained research assistants in two phases. The first phase consisted of a face-to face interview at home using a multidimensional structured questionnaire. The second phase consisted of a battery of physical function tests carried out in a community center.

For this co-project, the frailty criteria and CVD risk factors from the FIBRA Network's evaluation protocol were used.

Sample characterization data included: sex, age, number of medications used regularly in the last 3 months, number of diseases (none, one to two, or three or more) reported according to a list of nine items (cardiac disease, hypertension, stroke, diabetes, cancer, arthritis, pulmonary diseases, depression, and osteoporosis), and perceived health (very good/good, regular, or poor/very poor).

\section{Frailty criteria}

Five criteria were used to classify frailty according to Fried et al's phenotype: 6 low physical activity level, weakness, slow walking speed, unintentional weight loss, and perceived fatigue or exhaustion. Participants were classified as frail if they presented three or more of these criteria, pre-frail if they presented one or two criteria, and non-frail if they had none of them. ${ }^{6}$

To evaluate the physical activity level, the short version of the Minnesota Leisure Time Activities Questionnaire ${ }^{15}$ 
was used, which asked the individuals if they performed physical activities, the amount of exercises in the last 2 weeks, and the number of minutes dedicated to each activity. Based on this information, the metabolic equivalent (MET) for each activity was calculated in accordance with the recommendations of the Compendium of Physical Activities. ${ }^{16}$ The calories spent were calculated according to the following equation.

Calories spent $(\mathrm{kcal} / \mathrm{minute})=0.0175 \mathrm{kcal} \times \mathrm{kg}^{-1} \times \mathrm{min}^{-1}$ $\times$ MET $\times$ body weight $(\mathrm{kg})$.

The total amount of calories spent ( $\mathrm{kcal} /$ week) was attained by calculating the time spent carrying out the activities, taking into consideration the positive frailty criteria values equal to or lower than the lower quintile of the sample.

Unintentional weight loss in the last 12 months was evaluated based on self-report (affirmative/negative). If affirmative, the participant was asked to state the amount of weight (kg) lost. The loss of $\geq 4.5 \mathrm{~kg}$ or $\geq 5 \%$ of body weight in a 1 -year period was considered positive for frailty. ${ }^{6}$

Exhaustion was determined by self-report of fatigue as indicated through two questions from the Center for Epidemiological Studies - Depression ${ }^{17}$ questionnaire:

- "Did you feel that you had to exert yourself to perform your daily tasks?"

- "Were you unable to carry out your activities?"

There were four possible answers to each question: always, most of the time, occasionally, or rarely/never. Those who responded "always" or "most of the time" to any of the questions were considered to be frail. ${ }^{6}$

Weakness was measured by hand grip strength using a dynamometer in the dominant hand (model SH 5001; Saehan Corporation, Masan, South Korea). The participant was positioned according to the recommendations of the American Society of Hand Therapy. ${ }^{18}$ Three attempts were made and the mean was calculated (kgf). The participants whose average measurement was in the lowest $20 \%$ in sample distribution, adjusted by sex and body mass index (BMI), were considered frail. ${ }^{6}$

Walking speed was measured by the time required to walk a path of $8.6 \mathrm{~m}$ at usual pace, excluding $2 \mathrm{~m}$ for acceleration and $2 \mathrm{~m}$ for deceleration. The participants whose average of three attempts was in the lowest quintile of the distribution, adjusted by sex and height, were considered frail. ${ }^{6}$

All these tests representing the frailty criteria were categorized in terms of presence/absence.

\section{CVD risk factors}

The CVD risk factors considered in this study were selfreported hypertension or hypertension determined by blood pressure measurement, self-reported DM, obesity determined by BMI, waist circumference measurement, and smoking. A categorical rate score (zero to one, two to three, or four to five risk factors) was created based on these five risk factors. These factors are among the risks for CVD provided by the American Heart Association and the American College of Cardiology. ${ }^{19}$

To evaluate the nutritional state of the elderly individual, weight $(\mathrm{kg})$ was measured on a set of scales (GTech ${ }^{\text {TM }}$ Glass 3S; GM Sales and Services, New Delhi, India) and height (m) was measured by a ruler fixed to the wall. After obtaining the data, the BMI $\left(\mathrm{kg} / \mathrm{m}^{2}\right)$ was calculated and the participants were classified as underweight (BMI $<18.5 \mathrm{~kg} / \mathrm{m}^{2}$ ), normal $\left(18.5 \leq \mathrm{BMI}<25 \mathrm{~kg} / \mathrm{m}^{2}\right)$, overweight $\left(25 \leq \mathrm{BMI}<30 \mathrm{~kg} / \mathrm{m}^{2}\right)$ or obese $\left(\mathrm{BMI} \geq 30 \mathrm{~kg} / \mathrm{m}^{2}\right) .{ }^{20}$ The participants classified as obese were considered a positive risk for CVD.

The presence of hypertension was verified by self-report and by objective measurement. Blood pressure was measured twice in the sitting position through the right arm with an automatic digital device (model HEM-7421-INT; Omron Healthcare, Inc., Kyoto, Japan). Older adults were considered hypertensive and with positive CVD risk if they reported having a diagnosis of hypertension provided by a physician in the last year and/or if they presented a systolic blood pressure $>139 \mathrm{mmHg}$ and/or diastolic blood pressure $>89 \mathrm{mmHg}$ in the second objective measurement. ${ }^{21}$

Waist circumference was measured with the participant in a standing position with a nonelastic flexible tape halfway between the lowest rib and the upper iliac spine, roughly in line with the umbilicus. The cutoffs for waist circumference being a positive CVD risk were $\geq 102 \mathrm{~cm}$ for men and $\geq 88 \mathrm{~cm}$ for women. ${ }^{20}$

Another risk factor for CVD is DM. The participants who reported having a diagnosis of DM provided by a physician in the last year were considered a positive risk for CVD.

Current smoking information was reported by participants. They were classified as smokers (current habit), former smokers (those who quit this habit), and nonsmokers. The individuals with a current habit of smoking were considered a positive risk for CVD.

\section{Statistical analysis}

A descriptive and inferential data analysis was performed using SPSS ${ }^{\circledR} 13.0$ (SPSS, Inc., Chicago, IL, USA) with the level of significance established at $5 \%$ to all statistical tests. 
The Kolmogorov-Smirnov test was used to confirm normal distribution. The frailty phenotype comparison (dependent variable) was tested with the chi-square test or Fisher's exact test for comparison with categorical variables and by analysis of variance following Tukey's contrast test for quantitative variables. Multivariate logistic regression models were conducted to assess the odds for being frail or pre-frail related to the number of CVD risk factors. The models with adjustments were constructed using age (Model 2) and significant $(P<0.05)$ demographic and clinical covariates (Model 3). To verify agreement between self-reported and objective clinical measurements for blood pressure, the kappa coefficient was applied. Reliability was characterized as slight $(\kappa \leq 0.20)$, fair $(0.20<\kappa \leq 0.40)$, moderate $(0.40<\kappa \leq 0.60)$, substantial $(0.60<\kappa \leq 0.80)$, or almost perfect $(0.80<\kappa \leq 1.00){ }^{22}$

\section{Results}

The sample consisted of 761 community-dwelling older adults, $9.7 \%$ of whom were frail, $48.0 \%$ were pre-frail, and $42.3 \%$ were non-frail (Figure 1).

The majority of the sample were women (64.3\%), within the age strata of $65-74$ years $(71.0 \%)$, and overweight $(39.8 \%)$. According to the frailty phenotype, the individuals classified as frail and pre-frail were older (Tukey's contrast test: $P \leq 0.001$ ),

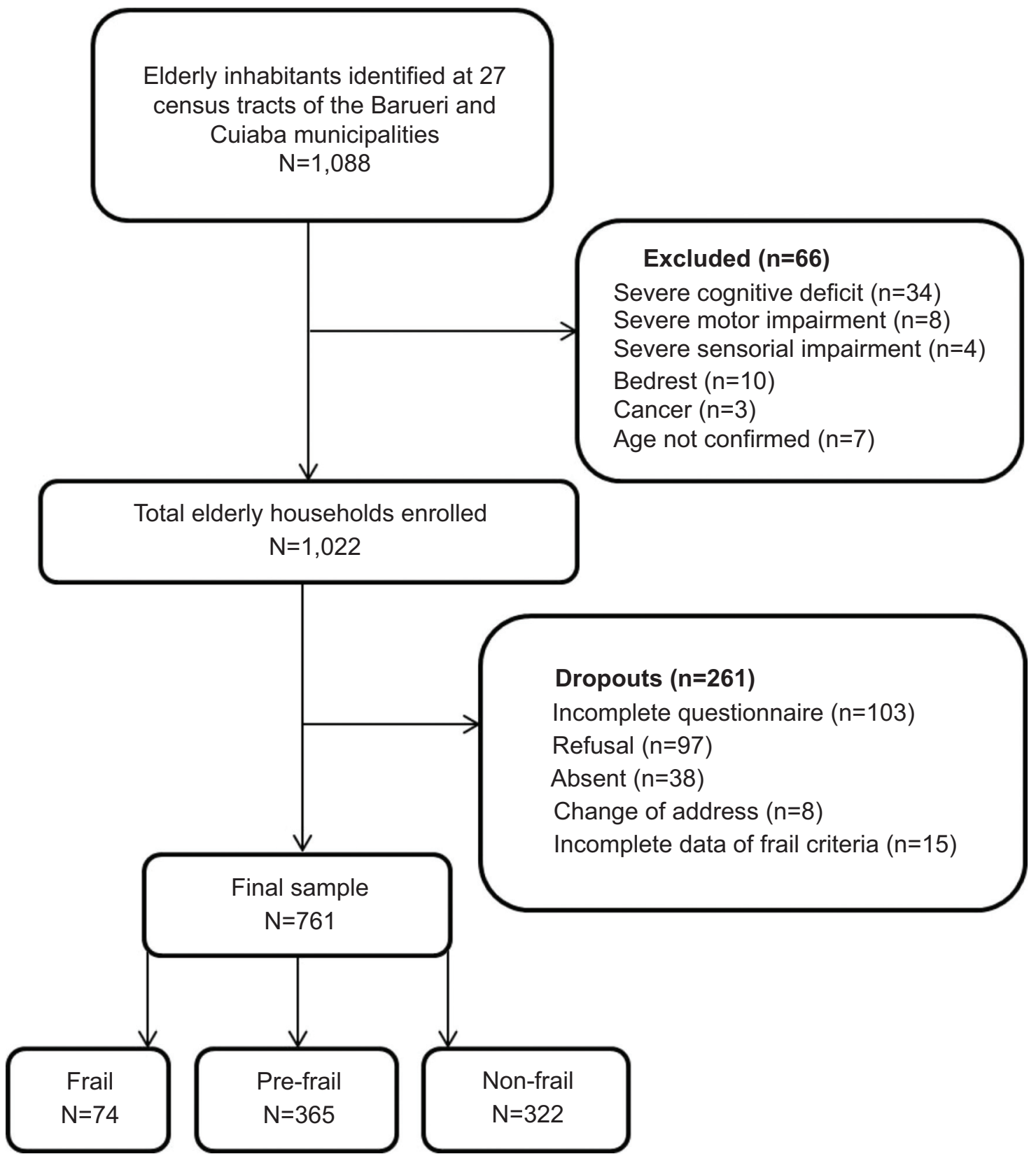

Figure I Study flow chart. 
presented a higher number of diseases (Tukey's contrast test: $P \leq 0.001 ; P \leq 0.001)$, were taking more medications regularly (Tukey's contrast test: $P=0.006 ; P=0.015$ ), and had poor selfrated health (Fisher's exact test: $P \leq 0.001 ; P=0.001$ ) compared to non-frail (Table 1). Frail older people also differed from pre-frail regarding advanced age and higher number of diseases (Tukey's contrast test: $P \leq 0.001 ; P=0.046$ ).

Among the frailty criteria, the one least observed was unintentional weight loss for those considered frail (44.6\%) and pre-frail $(21.4 \%)$. The frailty criterion most prevalent among frail individuals was slow walking speed (75.7\%) and fatigue among the pre-frail (29.6\%). All frailty criteria items were more prevalent among frail individuals when compared to pre-frail (Table 2).

There were few individuals with zero $(8.3 \%)$ or all five CVD risk factors $(0.7 \%)$. Most of the participants presented between two or three (47.0\%) CVD risk factors. A higher occurrence of four to five risk factors was observed among frail and pre-frail individuals when compared to non-frail (Fisher's exact test: $P=0.005 ; P=0.021$ ) (Figure 2).

In the multivariate adjusted model (Table 3 ) the presence of four or five CVD risk factors was independently associated with being frail and pre-frail, regardless of age, self-perceived health, number of diseases, and number of medications.
The chance of being frail or pre-frail increased almost twofold (odds ratio: 1.91; 95\% confidence interval: 1.02-3.57) in cases where the participant had four or five CVD risk factors.

With the exception of DM, no other CVD risk factors presented a significant difference regarding frailty groups (Table 2). DM was more prevalent among frail and pre-frail individuals when compared with non-frail (Fisher's exact test: $P \leq 0.001 ; P \leq 0.001)$.

Hypertension (84.4\%) was the most prevalent CVD risk factor and the least observed was smoking (10.4\%), both in the overall sample and for the groups of frailty (Table 2). With regard to smoking, $51.2 \%$ of the participants have or have had this habit in their lifetime. Nonetheless, no difference was observed related to past smoking history among frail $(\mathrm{n}=29 ; 39.1 \%)$, pre-frail $(\mathrm{n}=151 ; 41.3 \%)$, and non-frail $(\mathrm{n}=131 ; 40.0 \%)$ individuals (Fisher's exact test: $P=0.920)$. The prevalence of hypertension determined by blood pressure measurement was not statistically different (chi-square test: $P=0.891)$ among frail $(\mathrm{n}=48 ; 64.9 \%)$, pre-frail $(\mathrm{n}=231$; $n=63.3 \%)$, and non-frail individuals $(n=200 ; 62.1 \%)$. On the other hand, when self-reported hypertension was considered, there was less affirmative report among non-frail individuals ( $\mathrm{n}=196 ; 60.9 \%)$ (chi-square test: $P=0.003)$ in comparison with pre-frail $(\mathrm{n}=265 ; 72.6 \%)$ and frail $(\mathrm{n}=53$;

Table I Characterization of the total sample of community-dwelling elderly, with classification and comparison based on frailty group

\begin{tabular}{|c|c|c|c|c|c|}
\hline Variable & $\begin{array}{l}\text { Total } \\
\mathrm{N}=76 \text { I }\end{array}$ & $\begin{array}{l}\text { Non-frail } \\
N=322\end{array}$ & $\begin{array}{l}\text { Pre-frail } \\
N=365\end{array}$ & $\begin{array}{l}\text { Frail } \\
N=74\end{array}$ & $P$-value \\
\hline \multicolumn{6}{|l|}{ Sex, n (\%) } \\
\hline Female & $489(64.3)$ & $206(64.0)$ & $234(64.1)$ & $49(66.2)$ & $0.933 *$ \\
\hline Age (years), mean (SD) & $71.9(5.9)$ & $70.5(4.9)$ & $72.3(5.7)$ & $75.9(7.8)$ & $\leq 0.00 I^{\ddagger}$ \\
\hline \multicolumn{6}{|l|}{ Age group, n (\%) } \\
\hline $65-74$ years & $540(71.0)$ & $255(79.2)$ & $250(68.5)$ & $35(47.3)$ & \\
\hline $75-84$ years & $197(25.9)$ & $65(20.2)$ & $105(28.8)$ & $27(36.5)$ & $\leq 0.00 \mathrm{I}^{\dagger}$ \\
\hline$\geq 85$ years & $24(3.1)$ & $2(0.6)$ & $10(2.7)$ & $12(16.2)$ & \\
\hline Number of medications, mean (SD) & $2.6(2.1)$ & $2.3(1.9)$ & $2.8(2.1)$ & $3.2(2.7)$ & $0.002^{\ddagger}$ \\
\hline \multicolumn{6}{|l|}{ Number of diseases, $\mathrm{n}(\%)$} \\
\hline None & $87(I I .4)$ & $52(16.2)$ & $30(8.2)$ & $5(6.8)$ & \\
\hline $\mathrm{I}-2$ diseases & $374(49.2)$ & $184(57.1)$ & $163(44.7)$ & $27(36.4)$ & $\leq 0.00 \mathrm{I}^{\dagger}$ \\
\hline 3 or more diseases & $300(39.4)$ & $86(26.7)$ & $172(47.1)$ & $42(56.8)$ & \\
\hline \multicolumn{6}{|l|}{ Perceived health, $\mathrm{n}(\%)$} \\
\hline Good/very good & $373(49.0)$ & $187(58.1)$ & $162(44.4)$ & $24(32.4)$ & \\
\hline Regular & $333(43.8)$ & $122(37.9)$ & $172(47.1)$ & $39(52.7)$ & $\leq 0.00 \mathrm{I}^{\dagger}$ \\
\hline Poor/very poor & $55(7.2)$ & $13(4.0)$ & 31 (8.5) & II (14.9) & \\
\hline BMI $\left(\mathrm{kg} / \mathrm{m}^{2}\right)$, mean $(\mathrm{SD})$ & $27.3(4.9)$ & $27.2(4.7)$ & $27.5(5.0)$ & $27.3(5.2)$ & $0.723^{\ddagger}$ \\
\hline \multicolumn{6}{|l|}{ BMI, n (\%) } \\
\hline$<18.5 \mathrm{~kg} / \mathrm{m}^{2}$ & $18(2.4)$ & $8(2.5)$ & $8(2.2)$ & $2(2.7)$ & \\
\hline $18.5 \leq \mathrm{BMI}<25 \mathrm{~kg} / \mathrm{m}^{2}$ & $238(31.3)$ & $98(30.4)$ & $|2|(33.2)$ & $19(25.7)$ & $0.352^{\dagger}$ \\
\hline $25 \leq \mathrm{BMI}<30 \mathrm{~kg} / \mathrm{m}^{2}$ & $303(39.8)$ & $|4|(43.8)$ & $130(35.6)$ & $32(43.2)$ & \\
\hline$\geq 30 \mathrm{~kg} / \mathrm{m}^{2}$ & $202(26.5)$ & $75(23.3)$ & $106(29.0)$ & $21(28.4)$ & \\
\hline
\end{tabular}

Notes: *Chi-square test. ${ }^{\dagger}$ Fisher's exact test. ${ }^{\ddagger}$ Analysis of variance.

Abbreviations: BMI, body mass index; SD, standard deviation. 
Table 2 Prevalence of frailty criteria and risk factors for cardiovascular disease in community-dwelling elderly, with comparison based on frailty group

\begin{tabular}{|c|c|c|c|c|c|}
\hline Variable & $\begin{array}{l}\text { Total } \\
\mathrm{N}=76 \text { I }\end{array}$ & $\begin{array}{l}\text { Non-frail } \\
N=322\end{array}$ & $\begin{array}{l}\text { Pre-frail } \\
N=365\end{array}$ & $\begin{array}{l}\text { Frail } \\
N=74\end{array}$ & $P$-value \\
\hline \multicolumn{6}{|l|}{ Frailty criteria } \\
\hline Weight loss & III (14.6) & 0 & $78(21.4)$ & $33(44.6)$ & $\leq 0.00 I^{*}$ \\
\hline Exhaustion & $158(20.8)$ & 0 & $108(29.6)$ & $50(67.6)$ & $\leq 0.00 I^{*}$ \\
\hline Weakness & $154(20.2)$ & 0 & $100(27.4)$ & $54(73.0)$ & $\leq 0.001 *$ \\
\hline Slowness & $152(20.0)$ & 0 & $96(26.3)$ & $56(75.7)$ & $\leq 0.00 I^{*}$ \\
\hline Low physical activity level & $153(20.1)$ & 0 & $104(28.5)$ & $49(66.2)$ & $\leq 0.00 I^{*}$ \\
\hline \multicolumn{6}{|l|}{ CVD risk factors } \\
\hline Hypertension & $642(84.4)$ & $262(8 I .4)$ & $318(87.1)$ & $62(83.8)$ & $0.115^{\dagger}$ \\
\hline Diabetes & $189(24.8)$ & $56(17.4)$ & $107(29.5)$ & $26(35.1)$ & $\leq 0.00 \mathrm{I}^{\dagger}$ \\
\hline Smoking & $79(10.4)$ & $30(9.3)$ & $4 I(I I .2)$ & $8(10.8)$ & $0.708^{\dagger}$ \\
\hline Waist circumference & $321(42.2)$ & $|4|(43.8)$ & I5I (4I.4) & $29(39.2)$ & $0.701 *$ \\
\hline Obesity & $202(26.5)$ & $75(23.3)$ & $106(29.0)$ & $21(28.4)$ & $0.219 *$ \\
\hline
\end{tabular}

Notes: Data represent $\mathrm{n}(\%)$. *Chi-square test. 'Fisher's exact test.

Abbreviation: CVD, cardiovascular disease.

71.6\%). Agreement values of hypertension assessed by self-report and by blood pressure evaluation were slight in frail ( $\kappa=0.287 ; P=0.013)$, pre-frail ( $\kappa=0.128 ; P=0.012)$, and non-frail individuals $(\kappa=0.161 ; P=0.004)$. Table 4 reveals that some individuals sampled did not consider themselves as hypertensive, but they presented values compatible to high blood pressure on objective measures (51.8\%). Also, most of those who reported a diagnosis of hypertension did not have their blood pressure under control at the exact moment their blood pressure was checked (68.3\%).

\section{Discussion}

This study revealed the high prevalence of hypertension in the overall sample and high presence of risk factors for
CVD - four or five, especially DM, among frail and prefrail community-dwelling older adults. This data reinforces the idea that there are factors that are potentially harmful to the health of the elderly that can be modified and/or prevented.

The prevalence of frailty is variable in different studies around the world. ${ }^{23}$ This variability is commonly attributed to differences in the definition of frailty and its operationalization and the population studied. In a systematic review considering Fried et al's phenotype, also used in this study, the prevalence of frail individuals was 9.9\% (95\% CI: 9.6\%$10.2 \%$ ) and $44.2 \%$ (95\% CI: $44.2 \%-44.7 \%)$ to pre-frail, ${ }^{23}$ which is very similar to the levels of prevalence that were observed in the current study.

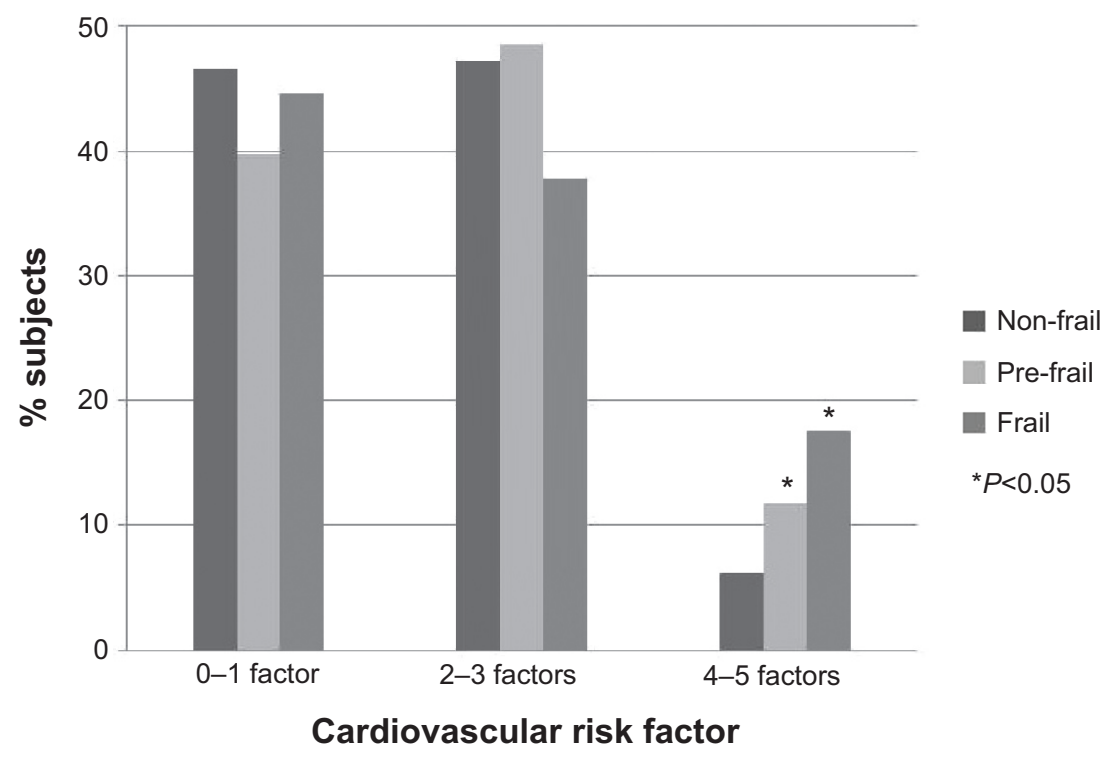

Figure 2 Distribution of risk factors for cardiovascular disease according to frailty group. 
Table 3 Multivariate regression analysis to estimate the odds of being frail or pre-frail according to the number of risk factors for cardiovascular disease in community-dwelling elderly

\begin{tabular}{|c|c|c|c|c|c|c|c|c|c|}
\hline \multirow[t]{2}{*}{ CVD risk factors } & \multicolumn{3}{|c|}{ Model I } & \multicolumn{3}{|c|}{ Model 2} & \multicolumn{3}{|c|}{ Model 3} \\
\hline & $\overline{O R}$ & $95 \% \mathrm{Cl}$ & $P$-value & OR & $95 \% \mathrm{Cl}$ & $\overline{P \text {-value }}$ & OR & $95 \% \mathrm{Cl}$ & $P$-value \\
\hline $0-I$ (reference) & - & - & - & - & - & - & - & - & - \\
\hline $2-3$ & 1.13 & $0.84-1.53$ & 0.406 & 1.18 & $0.87-1.61$ & 0.279 & 0.97 & $0.69-1.35$ & 0.860 \\
\hline $4-5$ & 2.36 & $|.35-4.1|$ & 0.002 & 2.90 & $1.64-5.12$ & $<0.001$ & 1.91 & I.02-3.57 & $0.04 I$ \\
\hline
\end{tabular}

Notes: Model I, not adjusted. Model 2, adjusted for age. Model 3, adjusted for age, number of diseases, number of medications, and self-perceived health. Abbreviations: $\mathrm{Cl}$, confidence interval; CVD, cardiovascular disease; OR, odds ratio.

In the present study most of the participants presented at least one of the five risk factors for CVD, even among those classified as non-frail. In a population-based study, nearly half of the individuals aged 30-69 years old presented two or more CVD risk factors (sedentary lifestyle, unsuitable eating habits, obesity, smoking, alcohol consumption, and high blood pressure $)^{9}$ showing that CVD risk factors are possibly carried through a substantial part of the life cycle. The data from this study calls attention to the fact that frail and pre-frail individuals present a higher number of associated CVD risk factors - four or five factors, in comparison to non-frail, thereby indicating a cumulative and interactive relationship between the increase of CVD risk factors and frailty. Most CVD results from unsuitable habits during the person's lifetime, and any risk factor left untreated over the course of many years increases the odds of developing such diseases. ${ }^{24}$ Thus, early identification and intervention in CVD risk factors in middle age can prevent a series of negative outcomes associated with CVD in old age, including cognitive decline, dementia, depression, disability, and frailty itself. ${ }^{10}$

Of the CVD risk factors, DM was the most prevalent among frail and pre-frail participants. A similar result was observed in the Cardiovascular Health Study with DM prevalent in $25 \%$ of the frail individuals, $18.2 \%$ of the pre-frail, and only $12 \%$ of the non-frail. ${ }^{25} \mathrm{DM}$ is one of the strongest risk factors for CVD, being as significant as atherosclerosis. ${ }^{26}$ Diabetic individuals present an increased risk, three to four times higher, of suffering a cardiovascular event and a double risk of mortality when compared to the general population. ${ }^{26}$ In a 12 -year survival analysis study, ${ }^{27}$ the increase by one point in the frailty rate was associated with an increase of $36 \%$ in mortality in the long term among individuals without DM compared with an increase of $93 \%$ in individuals with DM. Besides this, frail individuals were 2.6 times more likely to have a complication related to DM, regarding age, sex, and number of years living with the disease. The relationship between DM and frailty seems to be influenced by sarcopenia. The muscle impairment in diabetic people is a result of fat infiltration in the muscle tissue, higher insulin resistance levels, the increased levels of cytokines, and reduction in motor end plates. ${ }^{28,29}$ Thus, elderly diabetics present the necessary pathophysiological conditions to frailty development earlier than others. ${ }^{29}$

Hypertension was the most prevalent risk factor for CVD among older people in this study, regardless of frailty classification. Participants presented levels of blood pressure above the desirable parameters, which demonstrates a long-term additional factor of systemic deregulation and an increased risk of CVD, disability, and adverse health outcomes. In corroboration with the current study, no difference was observed in blood pressure objectively measured in a physician's office in the sitting, laying, and standing positions in frail, pre-frail, and non-frail subjects. ${ }^{30}$ The prevalence of self-reported hypertension, nearly $60 \%-70 \%$ in this study, was similar to the prevalence observed in the literature. ${ }^{31}$ However, it was identified that self-reported hypertension was less reported among non-frail individuals than among those who were classified as frail and pre-frail. The low rate

Table 4 Agreement between self-report and objective measurement of hypertension in community-dwelling elderly according to frailty groups

\begin{tabular}{|c|c|c|c|c|c|c|c|c|c|}
\hline & & \multicolumn{2}{|l|}{ Non-frail } & \multicolumn{2}{|l|}{ Pre-frail } & \multicolumn{2}{|l|}{ Frail } & \multicolumn{2}{|l|}{ Total } \\
\hline & & \multicolumn{2}{|c|}{ BP measured } & \multicolumn{2}{|c|}{ BP measured } & \multicolumn{2}{|c|}{ BP measured } & \multicolumn{2}{|c|}{ BP measured } \\
\hline & & Normal (n) & HTN (n) & Normal (n) & HTN (n) & Normal (n) & HTN (n) & Normal (n) & HTN (n) \\
\hline \multirow[t]{2}{*}{ Self-reported HTN } & No & 60 & 66 & 47 & 53 & 12 & 9 & 119 & 128 \\
\hline & Yes & 62 & 134 & 87 & 178 & 14 & 39 & 163 & 351 \\
\hline
\end{tabular}

Abbreviations: BP, blood pressure; HTN, hypertension. 
of agreement between self-reported and objectively measured hypertension is alarming, revealing that many participants did not know that they were hypertensive or even that they were undertreated. Similar results were observed in a Brazilian study of 1,494 older people in which $61.5 \%$ of participants had high blood pressure; of these, $76.6 \%$ were aware of having hypertension and $82.1 \%$ were on treatment. Among those who were undergoing treatment, only $38.8 \%$ had controlled hypertension. ${ }^{32}$ This is a public health issue that needs to be faced and requires effort from professionals and politicians to plan actions to prevent and/or control hypertension in primary health care.

The least observed CVD risk was smoking (10.4\%). This result positively revealed that most of the sample had abandoned this harmful habit. Smoking is considered the main cause of avoidable death. The decreased occurrence of smoking in advancing age is associated with the emergence of diseases that lead to recommendation of smoking cessation and the adoption of healthier behavior.

No connection was found between frailty, obesity, and waist circumference. Frailty is commonly related to weight loss. Nonetheless, recent studies observed that association with BMI occurs with poor nutritional state in frail elderly, either through malnutrition or obesity. ${ }^{33}$ Increased fat tissue is related to increased production of proinflammatory cytokines and mediators, such as interleukin-6 and C-reactive protein, which leads to a state of chronic inflammation present in the frailty syndrome. There is an increase in fat tissue with advancing age, regardless of BMI, known as sarcopenic obesity, in which there is a larger visceral fat deposit and especially an increase in fat infiltration to the muscles. ${ }^{34}$ This being so, BMI does not seem to be the best indicator of adiposity because it demonstrates that both the fat mass and the lean mass contribute to poor health in elderly people. ${ }^{35}$

The results of this study must be observed with caution since this is a cross-sectional study and causality between CVD risk and frailty could not be tested. Besides this, the frailty phenotype used in this study is basically comprised of rates of physical frailty, and does not include other markers such as cognitive decline and psychosocial aspects. Also, it did not include other risk factors for CVD, especially the laboratorial elements such as total cholesterol and triglycerides.

It is also important to highlight that one of the main risk factors for CVD is sedentarism. This factor was not included in this study because it is one of the components of frailty. The association between sedentarism, frailty, and CVD can be explained as being the lack of physical activity that progressively results in sarcopenia, ie, the decline in lean mass together with weakness. ${ }^{34}$ Sarcopenia demands a greater effort from older people to perform daily activities, with an increase in energy expenditure and cardiovascular and metabolic overload, eventually increasing the risks of transitioning to frailty, characterized by a reduction in functional reserve. ${ }^{4}$ This progressive decline of the functional mechanisms, on the other hand, exacerbates atherosclerosis and inflammatory markers involved in CVD. ${ }^{4}$

\section{Conclusion}

This study revealed the association between frailty and the presence of risk factors for CVD (four or five factors), especially DM. Frailty and CVD are more prevalent with advancing age and may cause adverse health outcomes; however, both conditions are preventable and their early detection is important to avoid the increase of comorbidity and disability among the elderly. ${ }^{9}$ These conditions share several risk factors such as physical inactivity and inadequate nutritional status. Thus, adequate assessment of the co-ocurrence of frailty and CVD could be useful to identify those older people in need of systematic intervention, thereby facilitating comprehensive health care for the elderly.

\section{Acknowledgment}

A support grant was received from the National Council for Scientific and Technological Development, Brazil CNPq, MCT-CNPq/MS-SCTIE-DECIT - (17/2006).

\section{Disclosure}

The authors report no conflicts of interest in this work.

\section{References}

1. Afilalo J, Karunananthan S, Eisenberg MJ, Alexander KP, Bergman H. Role of frailty in patients with cardiovascular disease. Am J Cardiol. 2009;103(11):1616-1621.

2. Gary R. Evaluation of frailty in older adults with cardiovascular disease: incorporating physical performance measures. J Cardiovasc Nurs. 2012; 27(2):120-131.

3. Newman AB, Gottdiener JS, McBurnie MA, et al. Associations of subclinical cardiovascular disease with frailty. J Gerontol A Biol Sci Med Sci. 2001;56(3):M158-M166.

4. Phan HM, Alpert JS, Fain M. Frailty, inflammation, and cardiovascular disease: evidence of a connection. Am J Geriatr Cardiol. 2008; 17(2):101-107.

5. Bergman H, Ferrucci L, Guralnik J, et al. Frailty: an emerging research and clinical paradigm - issues and controversies. J Gerontol A Biol Sci Med Sci. 2007;62(7):731-737.

6. Fried LP, Tangen CM, Walston J, et al. Frailty in older adults: evidence for a phenotype. J Gerontol A Biol Sci Med Sci. 2001;56(3): M146-M156. 
7. Roger VL, Go AS, Lloyd-Jones DM, et al. Heart disease and stroke statistics - 2012 update: a report from the American Heart Association. Circulation. 2012;125(1):e2-e220.

8. Fried LP. Epidemiology of aging. Epidemiol Rev. 2000;22(1): 95-106.

9. Pereira JC, Barreto SM, Passos VM. [Cardiovascular risk profile and health self-evaluation in Brazil: a population-based study]. Rev Panam Salud Publica. 2009;25(6):491-498. Portuguese.

10. Bouillon K, Batty GD, Hamer M, et al. Cardiovascular disease risk scores in identifying future frailty: the Whitehall II prospective cohort study. Heart. 2013;99(10):737-742.

11. Neri AL, Yassuda MS, Araujo LF, et al. [Methodology and social, demographic, cognitive, and frailty profiles of community-dwelling elderly from seven Brazilian cities: the FIBRA Study]. Cad Saude Publica. 2013;29(4):778-792. Portuguese.

12. Ferrucci L, Guralnik JM, Studenski S, Fried LP, Cutler GB Jr, Walston JD. Designing randomized, controlled trials aimed at preventing or delaying functional decline and disability in frail, older persons: a consensus report. J Am Geriatr Soc. 2004;52(4):625-634.

13. Folstein MF, Folstein SE, McHugh PR. "Mini-mental state". A practical method for grading the cognitive state of patients for the clinician. J Psychiatr Res. 1975;12(3):189-198.

14. Brucki SM, Nitrini R, Caramelli P, Bertolucci PH, Okamoto IH. [Suggestions for utilization of the mini-mental state examination in Brazil] Arq Neuropsiquiatr. 2003;61(3B):777-781. Portuguese.

15. Taylor HL, Jacobs DR Jr, Schucker B, Knudsen J, Leon AS, Debacker G. A questionnaire for the assessment of leisure time physical activities. J Chronic Dis. 1978;31(12):741-755.

16. Ainsworth BE, Haskell WL, Whitt MC, et al. Compendium of physical activities: an update of activity codes and MET intensities. $\mathrm{Med} \mathrm{Sci}$ Sports Exerc. 2000;32(9 Suppl):S498-S504.

17. Batistoni SS, Neri AL, Cupertino AP. [Validity of the Center for Epidemiological Studies Depression Scale among Brazilian elderly]. Rev Saude Publica. 2007;41(4):598-605. Portuguese.

18. Crosby CA, Wehbe MA, Mawr B. Hand strength: normative values. J Hand Surg Am. 1994;19(4):665-670.

19. Grundy SM, Pasternak R, Greenland P, Smith S Jr, Fuster V. Assessment of cardiovascular risk by use of multiple-risk-factor assessment equations: a statement for healthcare professionals from the American Heart Association and the American College of Cardiology. Circulation. 1999;100(13):1481-1492.

20. Klein S, Allison DB, Heymsfield SB, et al. Waist circumference and cardiometabolic risk: a consensus statement from Shaping America's Health: Association for Weight Management and Obesity Prevention; NAASO; the Obesity Society; the American Society for Nutrition; and the American Diabetes Association. Obesity (Silver Spring). 2007;15(5): 1061-1067.
21. Andrade JP, Nobre F. [VI Brazilian guidelines on hypertension]. Arq Bras Cardiol. 2010;95(1 Suppl):1-51. Portuguese.

22. Landis JR, Koch GG. The measurement of observer agreement for categorical data. Biometrics. 1977;33(1):159-174.

23. Collard RM, Boter H, Schoevers RA, Oude Voshaar RC. Prevalence of frailty in community-dwelling older persons: a systematic review. $J$ Am Geriatr Soc. 2012;60(8):1487-1492.

24. Singh M, Alexander K, Roger VL, et al. Frailty and its potential relevance to cardiovascular care. Mayo Clin Proc. 2008;83(10):1146-1153.

25. Walston J, McBurnie MA, Newman A, et al. Frailty and activation of the inflammation and coagulation systems with and without clinical morbidities: results from the Cardiovascular Health Study. Arch Intern Med. 2002;162(20):2333-2341.

26. Siqueira AF, Almeida-Pititto B, Ferreira SR. [Cardiovascular disease in diabetes mellitus: classical and non-classical risk factors]. Arq Bras Endocrinol Metabol. 2007;51(2):257-267. Portuguese.

27. Cacciatore F, Testa G, Galizia G, et al. Clinical frailty and long-term mortality in elderly subjects with diabetes. Acta Diabetol. 2013;50(2): 251-260.

28. Chen LK, Chen YM, Lin MH, Peng LN, Hwang SJ. Care of elderly patients with diabetes mellitus: a focus on frailty. Ageing Res Rev. 2010;9(Suppl 1):S18-S22.

29. Morley JE. Diabetes, sarcopenia, and frailty. Clin Geriatr Med. 2008; 24(3):455-469.

30. Bastos-Barbosa RG, Ferriolli E, Coelho EB, Moriguti JC, Nobre F, Lima NK. Association of frailty syndrome in the elderly with higher blood pressure and other cardiovascular risk factors. Am J Hypertens. 2012;25(11):1156-1161.

31. Chrestani MA, Santos IS, Matijasevich AM. [Self-reported hypertension: validation in a representative cross-sectional survey]. Cad Saude Publica. 2009;25(11):2395-2406. Portuguese.

32. Firmo JO, Barreto SM, Lima-Costa MF. The Bambui Health and Aging Study (BHAS): factors associated with the treatment of hypertension in older adults in the community. Cad Saude Publica. 2003;19(3):817-827.

33. Hubbard RE, Lang IA, Llewellyn DJ, Rockwood K. Frailty, body mass index, and abdominal obesity in older people. $J$ Gerontol A Biol Sci Med Sci. 2010;65(4):377-381.

34. Cruz-Jentoft AJ, Baeyens JP, Bauer JM, et al. Sarcopenia: European consensus on definition and diagnosis: report of the European Working Group on Sarcopenia in Older People. Age Ageing. 2010;39(4):412-423.

35. Cabrera MA, Wajngarten M, Gebara OC, Diament J. [Relationship between body mass index, waist circumference, and waist-to-hip ratio and mortality in elderly women: a 5-year follow-up study]. Cad Saude Publica. 2005;21(3):767-775. Portuguese.
Clinical Interventions in Aging

\section{Publish your work in this journal}

Clinical Interventions in Aging is an international, peer-reviewed journal focusing on evidence-based reports on the value or lack thereof of treatments intended to prevent or delay the onset of maladaptive correlates of aging in human beings. This journal is indexed on PubMed Central, MedLine,

\section{Dovepress}

CAS, Scopus and the Elsevier Bibliographic databases. The manuscript management system is completely online and includes a very quick and fair peer-review system, which is all easy to use. Visit http://www.dovepress. com/testimonials.php to read real quotes from published authors. 